\title{
Co-simulation of a Rooftop Greenhouse and a School Building in London, UK
}

\author{
Melanie Jans-Singh ${ }^{1}$, Rebecca Ward ${ }^{1,2}$, Ruchi Choudhary ${ }^{1,2}$ \\ ${ }^{1}$ University of Cambridge, Cambridge, UK \\ ${ }^{2}$ Alan Turing Institute, London, UK
}

\begin{abstract}
Recent findings suggest that hydroponic rooftop greenhouses could be more efficient when combined with waste streams in cities (heat, $\mathrm{CO}_{2}$, wastewater, compost). While there are established methodologies for building energy simulation and simulation of controlled environment greenhouses, there is a gap in our understanding of the combined performance. This paper addresses this deficit for school buildings in London, UK, where urban agriculture is of increasing interest. A building scale energy simulation of an archetype school building in London is developed in Energy Plus (E+) and co-simulated with a validated Greenhouse Energy Simulation (GES) model of a rooftop greenhouse. This novel combined simulation estimates the potential for heat recovery and reduction of ventilation demand in the classroom and enables evaluation of strategies to reach optimal environmental conditions in the greenhouse itself.
\end{abstract}

\section{Introduction}

Urban farming offers a solution to growing concerns of cities' environmental impacts, and is a step towards thinking more sustainably about our cities. Urban population is set to increase by 2.6 billion people by 2050, representing over $70 \%$ of global population, and the current stress on available resources for water, energy, infrastructure and transport will soar (Martellozzo et al., 2014). Urban farming is prevalent around the world, and Orsini et al. (2013) suggests over 100 million people are already engaged in urban agriculture worldwide, with systems ranging from simple edible roof gardens, to advanced plant factories (Kozai, 2016) and building integrated agriculture (Sanyé-Mengual et al., 2015). While global food production accounts for a third of the world's land use and greenhouse gas emissions, greenhouses offer a potential for food production with a smaller footprint, reducing the risk of flooding and damaging effects of fertilisers (Kulak et al., 2013). Goldstein et al. (2016) talk of a "renaissance of urban agriculture in the world's wealthy, northern cities" as new technologies like hydroponics, with their significantly higher yields and water recycling ratio per square metre than conventional farming, offer the promise of competing with rural agriculture. However, the ben- efits of reduced food miles may be overwhelmed by the energy inputs and inefficient use of production outputs. Over the past decade, research into urban agriculture has developed considerably: from socioeconomic analyses (Specht et al., 2013), to speculative futuristic ideas (Despommier, 2011), and cost benefit comparisons of alternatives for reusing roofs in cities (Benis et al., 2018).

As urban farming and planning green spaces become more highly prioritised in cities such as London and growing food is increasingly on the school curriculum, it is important to analyse the wider impacts of integrating greenhouses into school buildings (Nadal et al., 2018). The precedent for integrated greenhouses in schools is growing: three out of four schools in London have allotments and integrate growing food in their curriculum (Capital Growth, 2016). Schools are increasingly using greenhouses as green classrooms (Thomaier et al., 2015), especially in primary and secondary schools (Nadal et al., 2018). For instance, the Greenhouse Project in New York has, as shown in Figure 1, built 86 labs containing hydroponic greenhouses on school roofs and old classrooms "to educate students and teachers about the science of sustainability" (New York Sun Works, 2018).

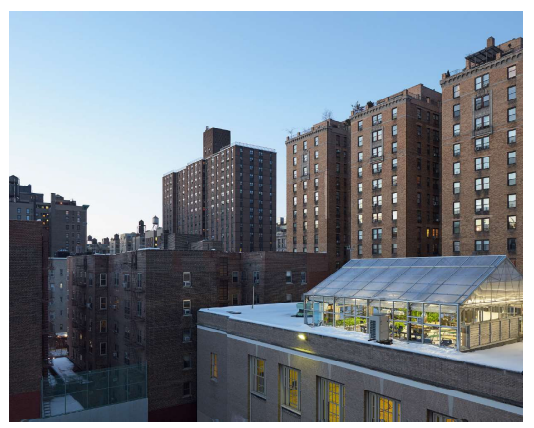

Figure 1: Hydroponic greenhouse on a school roof in New York (New York Sun Works, 2018).

The potentially high energy cost of hydroponic rooftop greenhouses could be offset by enhancing the symbiotic relationship between a greenhouse and the host building (Nadal et al., 2017). However, this is only possible if the impact of plants on indoor environment is quantified in terms of temperature, humidity, and $\mathrm{CO}_{2}$ levels. However, examples of cosimulating plants in regular buildings have been lim- 


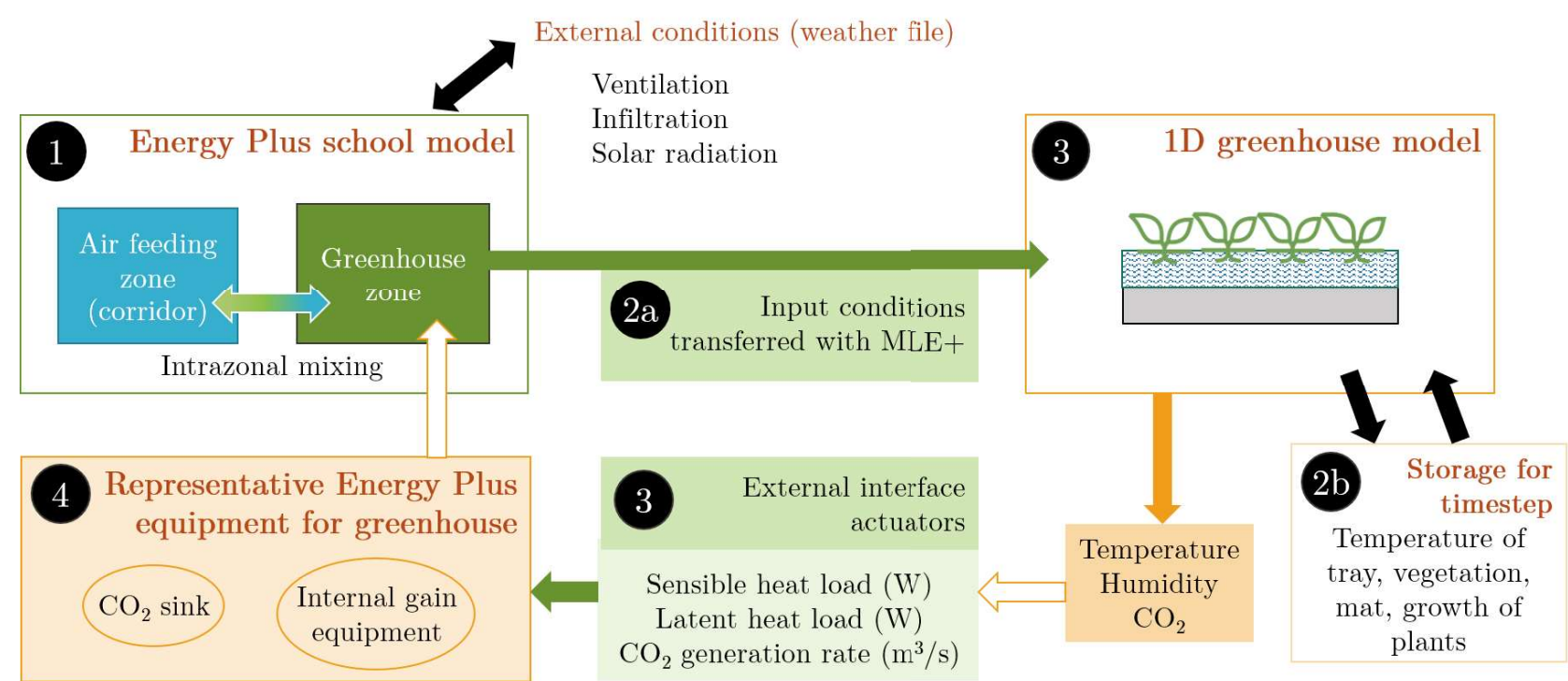

Figure 2: Diagram of the co-simulation model of a school building energy simulation in Energy Plus, and a heat and mass transfer greenhouse model in MATLAB.

ited. Ward et al. (2015) created a heat and mass transfer model representing transpiration, photosynthesis, and crop growth in an enclosed environment, based on Vanthoor (2011). This was integrated into building energy simulations using TRNSYS to analyse the effect of a composite greenhouse/office building located in London, UK (Ward et al., 2015) and to a university building that incorporates hydroponics in open plan offices Jans-Singh et al. (2018).

Rooftop greenhouses have also been modelled in combination with EnergyPlus (E+), one of the most commonly used building energy simulation software. Léveillé-Guillemette and Monfet (2016) evaluated different heating configurations for a rooftop solar greenhouse in Canada, but they did not include the effects of plants, even though they were aware they would influence the demand profile. Benis et al. (2017) and Nadal et al. (2017) developed a rooftop greenhouse model for Mediterranean climates, and represented the humidity and temperature change of the greenhouse using the Energy Plus evaporative cooling system. The representations of the plant transpiration and photosynthesis in these models were found to be limited.

The co-simulation developed in this paper enables the analysis of heat and mass transfer between an EnergyPlus zone and a greenhouse model. Expanding EnergyPlus to include the effects of plants indoors allows to determine how building air flows can be transferred between zones to increase crop yield and minimise building energy use, while being a flexible tool to test different building parameters and geometries. The components of the co-simulation tool are illustrated in Figure 2. The structure of this paper is as follows: (i) development of a building energy simulation for an archetype school building model (Part (1) of
Figure 2); (ii) development of a representative greenhouse model (Part (3) of Figure 2), (iii) co-simulation of the two models (Part (2a), (2b), (3) and (4) of Figure 2). The results section discusses possible outputs of the co-simulation.

\section{Archetype of secondary school building}

Figure 3 shows the total energy use (thermal and electrical) of the 620 schools in Central London, plotted against headcount of students, derived from combining data from Display Energy Certificates (DEC) (DCLG, 2017) and National Statistics for Schools by postcode (DfE, 2018). Based on this information, we chose to build an archetype model for a secondary school building due to its larger floor area, greater school student numbers, and average energy use intensity. The Energy Plus model builds upon the detailed probabilistic building energy model developed by Tian and Choudhary (2012), and on gathered building stock information.

The school building is designed for 900 students according to the Building Bulletin guidelines by the Department for Education and Skills (DfE, 2014), and has a floor area of $7680 \mathrm{~m}^{2}$ (Figure 3). The school has three storeys, to match the average building height of 10 to $14 \mathrm{~m}$ for school buildings in London found with the land use and building type database UKMap (The GeoInformation Group, 2017). The school area is divided into 53 zones, organised by orientation, floor and usage type. The 7 usage types are: classrooms (teaching and learning areas), circulation (hallways and entrance), storage and staffrooms, toilets, dining area and gym. Schedules for occupants, equipment and lighting are from DfE (2003). Building fabric and materials are chosen as representative from BRE (2016). Display Energy Certificates (DEC) data 


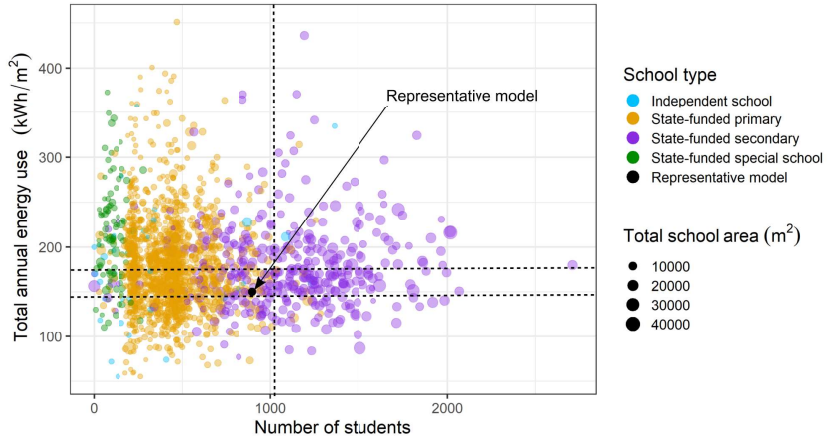

Figure 3: Total energy use (thermal and electrical) of the 620 schools in Central London, plotted against headcount of students. Data from combined DEC certificates (DCLG, 2017) and National Statistics for Schools merged by postcode (DfE, 2018). The black point shows where our model situates itself. The vertical dashed lines mark the median headcount (vertical) for secondary schools, while the horizontal dashed lines mark the best practice (25th percentile) and median energy use.

showed that $90 \%$ of educational buildings in Greater London were heated with natural gas and naturally ventilated. The natural ventilation minimum limits were set for each zone from the natural ventilation for schools guide (DfE, 2018). As we are interested in the change of building energy demand when integrating a greenhouse, we chose to represent the HVAC system with an Ideal Loads System to meet occupant comfort levels and thus assuming a highly efficient system, not limited by supply capacity. The annual total energy demand came to $150 \mathrm{kWh} / \mathrm{m}^{2}$, placing the school within the best practice (refurbished or newer) schools (Figure 3). This is expected since we are modelling demand, which is often a conservative estimate of actual energy use, and because the energy use intensity data in DEC Certificates represents the entire school building complex, which may include additional buildings with varied energy consumptions.

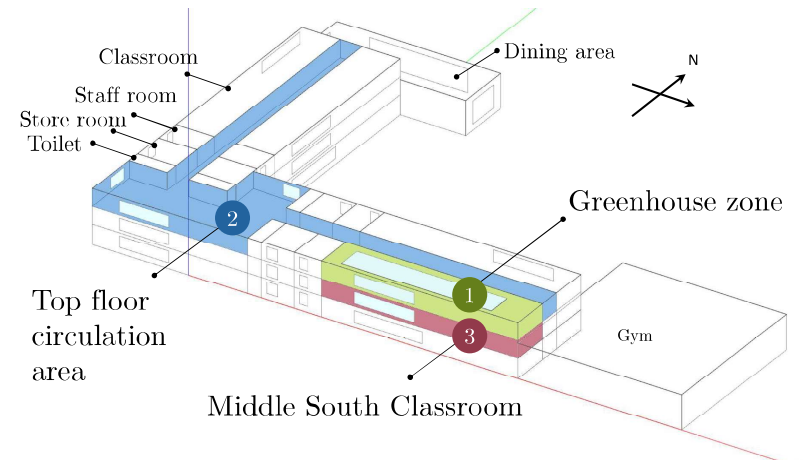

Figure 4: Representation of the school building model, with zones of interest.

The three zones in the school building model that are of particular interest are illustrated in Figure 4.

- Zone 1 is the Greenhouse Zone. It is located on the top floor with a large roof window to allow sufficient transmission of light to the plants, with shading in operation when the room temperature reaches $35{ }^{\circ} \mathrm{C}$. Its occupancy schedule is set at a classroom visit at $1 \mathrm{pm}$ by a group of 13 students on weekdays and two maintenance visits of two people in morning and evening on weekdays. This zone acts as a shell for the greenhouse and all input-output exchanges between the E+ and the Greenhouse Energy Simulation model occur through this zone.

- Zone 2 is the top floor circulation area, called "the Corridor". As students fill this area regularly, the $\mathrm{CO}_{2}$ levels reach $1400 \mathrm{ppm}$, and the temperatures are warm. The heated and $\mathrm{CO}_{2}$ rich air in this zone is used as an input for the Greenhouse Zone through "air mixing".

- Zone 3 represents the south facing classroom on the middle floor, hereafter known as "the Classroom". The high occupancy rate leads to very high $\mathrm{CO}_{2}$ levels and temperatures, requiring significant energy use for cooling and ventilation to meet occupancy comfort levels. The effects of mixing the air from the Greenhouse Zone into this Classroom will be analysed.

As aforementioned, all input-output exchanges between the E+ and the Greenhouse Energy Simulation (GES) model occur only through zone 1 - the Greenhouse Zone. Any change in temperature in the $\mathrm{E}+$ model of the Greenhouse Zone takes into account heat from the internal loads in the zone, the temperatures of the zone surfaces, infiltration and ventilation from the outside air, and the heat transfer due to internal air mixing with Zone 2 (the Corridor Zone). The surface temperatures, as calculated by the E+ Greenhouse Zone are transferred to the GES model at each time-step.

In $\mathrm{E}+$, the net heat balance at any inside surface is calculated as:

$\underbrace{q_{L W X}^{\prime \prime}+q_{S W}^{\prime \prime}+q_{L W S}^{\prime \prime}+q_{s o l}^{\prime \prime}}_{\text {Radiation }}+\underbrace{q_{k i}^{\prime \prime}+q_{c o n v}^{\prime \prime}+q_{a d d}^{\prime \prime}}_{\text {Conduction/Convection }}=0$

where $q_{L W X}^{\prime \prime}$ is the longwave radiant exchange (LW) from internal surfaces, $q_{S W}^{\prime \prime}$ is the shortwave radiation from any internal lights, $q_{L W S}^{\prime \prime}$ is the LW radiation from internal equipment, $q_{k i}^{\prime \prime}$ conduction through the wall, $q_{\text {sol }}^{\prime \prime}$ is the solar radiation, $q_{\text {conv }}^{\prime \prime}$ is the convective heat flux, and $q_{a d d}$ is the additional sensible heat transferred back from the GES model to the E+ Greenhouse Zone.

\section{Greenhouse Energy Simulation model}

\section{Model Overview}

The Greenhouse Energy Simulation (GES) model is a one dimensional heat and mass transfer model developed in MATLAB (Ward et al., 2018). The model 
has been validated for a rooftop greenhouse (Ward et al., 2015) and an underground controlled environment hydroponic farm (Ward et al., 2018).

The conceptualisation of a hydroponic unit in the model is shown in Figure 5, and the heat and mass flows between the identified nodes are illustrated in Figure 6. The plant module elements are represented by the combination of the three nodes: plant $(p)$, mat (m) and (tray), with parameters varying with planted area. Light input can be added through node (l). The boundary conditions are specified for the ceiling (c) and the floor (f) and are assumed constant over the timestep when combined with the E+ surface temperatures. The node of most interest for output is (i) representing internal air. The GES model can thus simulate different levels of mat saturation depending on irrigation and crop growth rate variation as with the changing Leaf Area Index (LAI).

The sensible heat flows modelled are convection (c), radiation (r), and conduction (cd), as functions of the temperature difference between the elements of interest. Ventilation was only included when running the GES model independently, and not for the cosimulation. Incoming solar radiation was directly input from the transmitted solar radiation produced by E + for the given zone geometry. Latent heat flows (lh) are modelled with the Penman-Monteith equation for transpiration (Equation 2), while evaporation and condensation are a function of the difference between the saturation vapour pressure transpiration of the component and the air.

Transpiration $T$ is a function of the difference in moisture content at the plant surface $X_{p}$ and the internal air $X_{i}$, the LAI, the latent heat of vaporisation of the air $h_{f e}$, and $r_{a}$ and $r_{s}$ the aerodynamic and stomatal resistance to vapour transfer respectively $(\mathrm{s} / \mathrm{m})$.

$$
T=L A I \times h_{f e} \frac{1}{r_{a}+r_{s}}\left(X_{p}-X_{a}\right)
$$
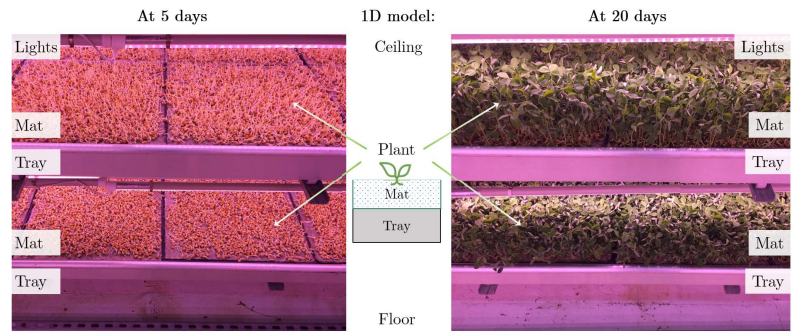

Figure 5: Representation in $1 D$ of a hydroponic module in Growing Underground.

The change in carbon dioxide density $C\left(\mathrm{~kg} / \mathrm{m}^{2}\right)$ is calculated with the photosynthesis model proposed by Vanthoor (2011). It estimates the change of $\mathrm{CO}_{2}$ as a function of mass of carbohydrates $M C$ in total $M_{c}$, in the buffer $M C_{b u f}$, fruit $M C_{\text {fruit }}$, leaf $M C_{\text {leaf }}$ and stem $M C_{\text {stem }}$ to the internal air $i$ (Equation 3).

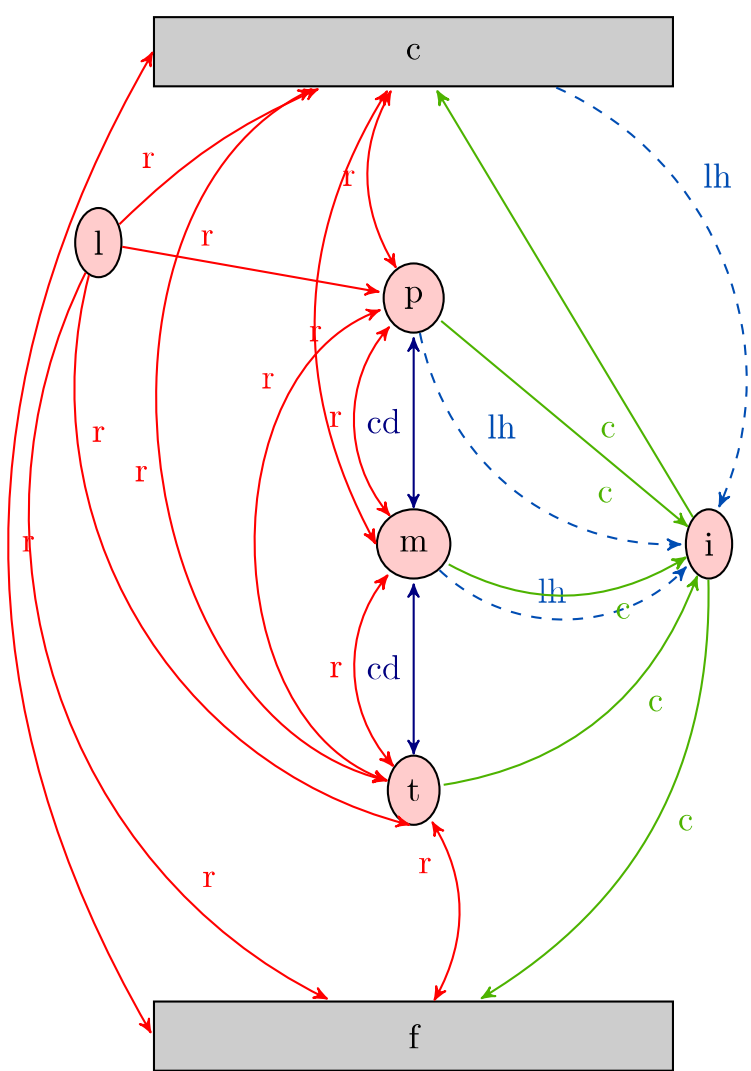

Figure 6: Nodal representation of the heat transfer processes for simulation of a $1 D$ slice through the greenhouse. Radiation ( $r$ in red), conduction ( $c d$ in black), convection (c green), and latent heat transfer (lh in blue). Each element $f$ (floor), $t$ (tray), $m$ (mat with growing media), $p$ (plant), $c$ (ceiling), $l$ (light source) constitute a layer $j$ of the model.

$$
\begin{aligned}
\frac{d C}{d t}= & \frac{M_{c}}{M_{\text {carb }}}\left(M C_{b u f \rightarrow i}+M C_{f r u i t \rightarrow i}+\right. \\
& \left.M C_{\text {leaf } \rightarrow i}+M C_{\text {stem } \rightarrow i}-M C_{i \rightarrow b u f}\right)
\end{aligned}
$$

\section{Model of the School's Greenhouse in GES}

The building geometry and properties of the GES model are set to match those of the Greenhouse Zone of the $\mathrm{E}+$ model. As an initial test, the GES model was run independently from $\mathrm{E}+$ for a room with the same design conditions as the Greenhouse Zone in Figure 4, to understand the expected performance of the greenhouse. The effect of air changes per hour, planted area and input air conditions could be ascertained, and created a reference to compare the cosimulation results with. The independent GES model was run for two input conditions: (a) Greenhouse Ventilated with outside air, and (b) Greenhouse ventilated with heated and $\mathrm{CO}_{2}$ rich air from the Corridor (Zone 2 of the $\mathrm{E}+$ model). Table 1 shows that the crops grow more when the Greenhouse is ventilated with warmer and $\mathrm{CO}_{2}$ rich air from the corridor than when ventilated with outside air. As expected, the resulting Greenhouse temperatures are 


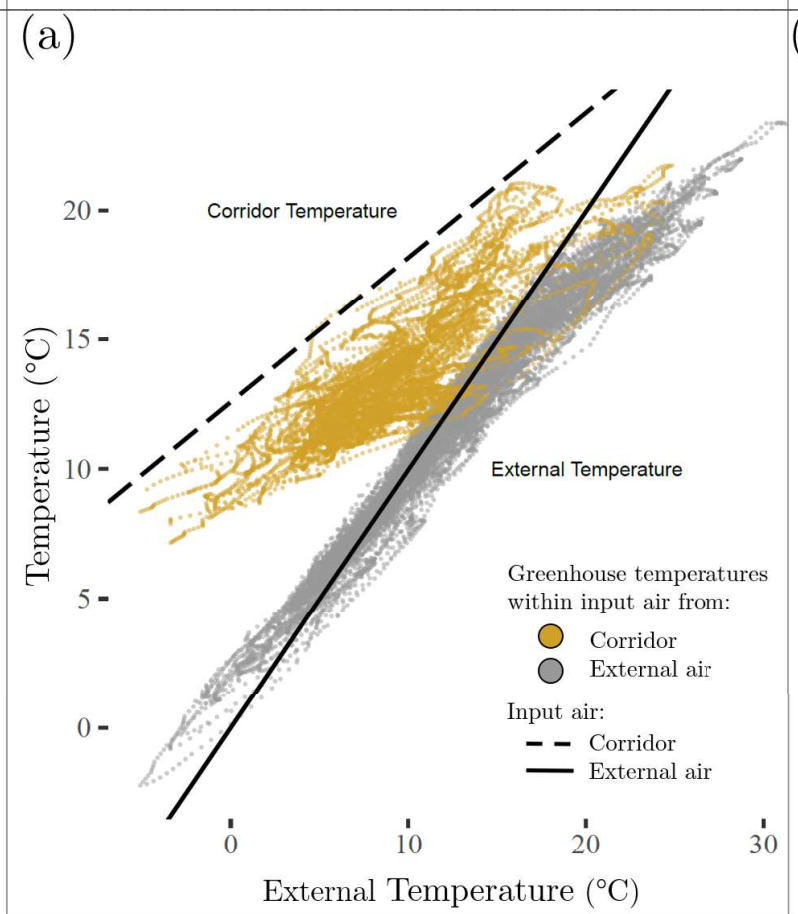

(b)

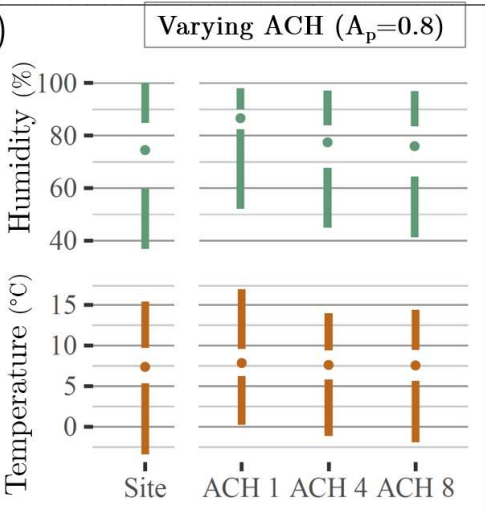

Varying $A_{p}(\mathrm{ACH}=3)$

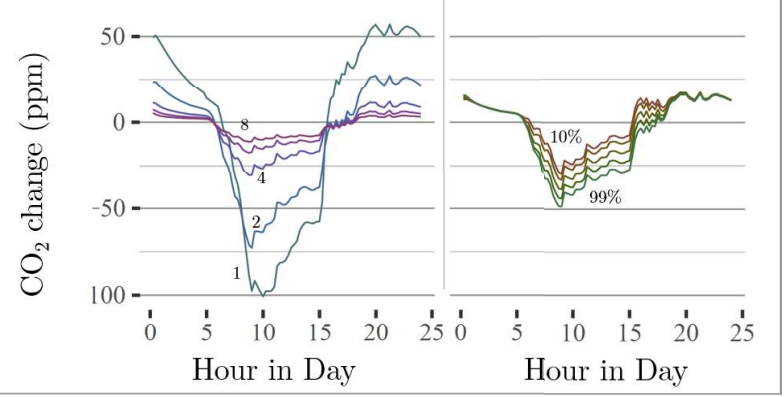

Figure 7: (a) Temperature modelled by GES as a function of corridor temperature (dashed, yellow) and external temperature (solid, grey). (b) Effect on temperature, relative humidity, and daily $\mathrm{CO}_{2}$ level of varying the air change per hour $(A C H)$ and planted area $\left(A_{p}\right)$ in the GES model.

higher than when ventilated with air from the corridor (Figure 7a). Furthermore, note that when the input conditions are colder, the greenhouse temperatures are higher than input air due to solar radiation and thermal inertia warming the plant module. However, under sufficiently warm conditions, the greenhouse is slightly cooler than outside air owing to the cooling effect of crop transpiration.

Table 1: Mass of fruit, leaf and stem $(\mathrm{kg})$ grown over 90 days with different input conditions.

\begin{tabular}{|c|c|c|c|}
\hline Input conditions & $C_{\text {fruit }}$ & $C_{\text {leaf }}$ & $C_{\text {stem }}$ \\
\hline External & 0.24 & 6.42 & 1.13 \\
Corridor & 0.43 & 8.87 & 1.15 \\
\hline
\end{tabular}

Figure $7 \mathrm{~b}$ shows some further outputs from the independent GES Greenhouse model, by varying air change per hour and planted area over three days in January, April, July and October. At lower ventilation rates (low $\mathrm{ACH}$ ), the humidity levels and temperatures in the Greenhouse are higher, but $\mathrm{CO}_{2}$ levels decrease. For a given $\mathrm{ACH}$ rate, varying the planted area has little effect on $\mathrm{CO}_{2}$ levels and temperature, but causes a significant increase in humidity (Figure $7 \mathrm{~b}$ ). To maintain a balance between excessive humidity (over $80 \%$ increases risk of disease), yet maintaining sufficiently high temperatures and $\mathrm{CO}_{2}$ levels, an ACH of 3 was chosen for the greenhouse design.

\section{Co-simulation of the $\mathrm{E}+$ Greenhouse Zone and GES model}

The two models are co-simulated at every timestep using the MLE+ tool (Bernal et al., 2014), which configures an external interface with MATLAB to act like a Building Controls Virtual Test Bed (BCVTB). The $\mathrm{E}+$ Ptolemy II external interface sends a packet of input data at every timestep to MATLAB which runs the GES model, and sends a packet back to E+. The environmental conditions in the Greenhouse Zone in the $\mathrm{E}+$ model can thus be input into the GES model to estimate the co-benefits of the coupled configuration, specifically the effect of plants on the air quality (humidity, temperature and $\mathrm{CO}_{2}$ ), and the impact of waste $\mathrm{CO}_{2}$ from the building on plant growth. Table 2 summarises the inputs from $\mathrm{E}+$ into the greenhouse model (part (2a) of Figure 2).

Table 2: Parameters from E+ Input to GES model.

\begin{tabular}{|l|l|c|}
\hline Input zone & Parameter & Unit \\
\hline GH Zone & Temperature & ${ }^{\circ} \mathrm{C}$ \\
GH Zone & Relative Humidity & $\%$ \\
GH Zone & $\mathrm{CO}_{2}$ & $\mathrm{ppm}$ \\
GH Zone floor & Temperature & ${ }^{\circ} \mathrm{C}$ \\
GH ceiling & Temperature & ${ }^{o} \mathrm{C}$ \\
GH zone & Solar radiation trans- & $\mathrm{W}$ \\
& mitted through window & \\
Site & Sky temperature & ${ }^{\circ} \mathrm{C}$ \\
Site & Wind speed & $\mathrm{m} / \mathrm{s}$ \\
Site & Air pressure & $\mathrm{Pa}$ \\
\hline
\end{tabular}

The timestep chosen for the co-simulation was 15 minutes for three reasons:

- to maximise the potential of $\mathrm{E}+$, which is more optimal with a smaller timestep to maximise the potential of the Predictor-Corrector approach;

- the GES model is more reliable with longer timesteps to allow sufficient iterations for feedback between crop growth and heat transfer; 
- to minimise the impact of co-simulation assumptions (boundary conditions from E+ remain constant over the timestep in the GES model).

The resulting change in temperature, relative humidity and $\mathrm{CO}_{2}$ concentration calculated by the GES model is passed back to the Greenhouse Zone of the $\mathrm{E}+$ model with the following three representative elements (part (4) of Figure 2):

1. Sensible heat gain (Watts) using the Other Equipment component with a Fraction Radiant of 1 (Equation 4).

2. Latent heat gain (Watts) using the Other Equipment component with a Fraction Latent of 1.

3. Carbon Dioxide gain using the Zone Contaminant Source or Sink component, with a volumetric generation rate. The external interface actuator must be a value between 0 and 1 (Equation 6).

E+ then updates the Greenhouse Zone conditions given the sensible heat, latent heat and, carbon dioxide change in the room due to the plants, as calculated by the GES model (part (1) of Figure 2). The sensible heat gain $S H$ in $\mathrm{W}$ is calculated in the timestep $\Delta T$ in $\mathrm{h}^{-1}$ by:

$$
\Delta S H=\frac{T_{\text {out }}-\text { Tin }}{\Delta T} \rho_{a} c_{p} V_{\text {room }}
$$

where the heat capacity of the air $c_{p}=0.28 \mathrm{Wh} / \mathrm{kg} \mathrm{K}$ at $25^{\circ} \mathrm{C}, \rho_{a}$ the density of the air, $V_{\text {room }}$ the volume of the room, and $T_{\text {out }}$ is the updated temperature output from the GES model in Kelvin.

The latent heat gain $L H$ is calculated by:

$$
\Delta L H=\frac{X_{\text {out }}-X_{\text {in }}}{\Delta T} h_{f e} V_{\text {room }}
$$

where $X_{\text {out }}$ is the air moisture content output from the GES model in $\mathrm{kg} / \mathrm{m}^{3}$ and $X_{i n}$ is the $\mathrm{E}+$ input air moisture content .

The volumetric change in $\mathrm{CO}_{2}\left(\mathrm{~m}^{3} / \mathrm{s}\right)$ fed back to $\mathrm{E}+$ is calculated from the difference of $C_{\text {out }}$ and $C_{i n}$, where $C_{\text {out }}$ is the density of carbon dioxide output from the GES model in $\mathrm{kg} / \mathrm{m}^{3}$ :

$$
\Delta\left(C \mathrm{O}_{2}\right)=\frac{C_{\text {out }}-C_{\text {in }}}{\Delta T \rho_{a}} V_{\text {room }}\left(-1 \times 10^{-3}\right)
$$

Plant transpiration in the GES model causes latent heat increase in the air and a decrease of vegetation temperature, thus cooling the air and increasing humidity. Figure 8 compares the temperature and relative humidity in the Greenhouse Zone for three days in August for the independent GES model, and the two stages of the co-simulation model (the CoSim GES and net CoSim output from E+).

Without plants (black line in Figure 8), the independent GES and co-simulation outputs are the same, verifying that both models represent the heat and mass transfer through the zone in the same manner.
The dotted blue line in Figure 8 shows the impact of the plants (modelled by GES in the co-simulation process), and the solid blue line shows the net CoSim output from $\mathrm{E}+$. In this instance, no additional heating, cooling, occupants or artificial lighting are included in the model. Figure $8 \mathrm{~A}$ shows that temperatures decrease more during the daytime than night time. This is because the plants emit heat during the night due to stored solar radiation, while they lose more latent heat during the day as they photosynthesize and thus transpire more. In addition, Figure $8 \mathrm{~B}$ shows that $\mathrm{E}+$ controls the net increase in humidity resulting from plants' transpiration through ventilation and condensation of the moisture from the zone surfaces.
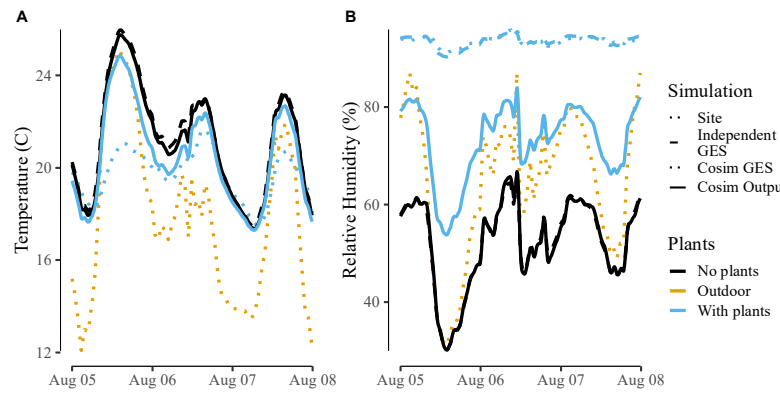

Figure 8: Temperature and humidity 6th-8th August when simulating without plants (black), and fully with plants (blue). The solid line represents the cosimulation outputs, while dotted lines are outputs from the GES model.

\section{Air Exchange between the greenhouse and the classroom}

Without a ventilation rate of at least $4 \mathrm{ACH}$, in line with the BB101 guidelines, the $\mathrm{CO}_{2}$ levels in the Classroom Zone (Zone 3) range around 3000 ppm during the day, far beyond the regulations to not exceed 1500 ppm during school hours (DfE, 2018). Figure 9 shows the mean $\mathrm{CO}_{2}$ concentration in the Classroom Zone when ventilated with external air compared with air mixing from the greenhouse zone, with different planted areas. The mean $\mathrm{CO}_{2}$ levels reached using four ACH with both these strategies were similar, averaging around $530 \mathrm{ppm}$. Increasing the planted area in the greenhouse did not cause a significant reduction in $\mathrm{CO}_{2}$, when the classroom was occupied less than 16 days. However with higher initial $\mathrm{CO}_{2}$ levels due to higher zone occupancy, the $\mathrm{CO}_{2}$ uptake from the plants increased, thus improving the air quality in the classroom by a greater extent.

Figure 10 compares the energy demand for heating and cooling of the Classroom when using external air for ventilation or mixing air from from the Greenhouse Zone. The results show a significant decrease in heating demand in winter, and variable results in summer. For instance, heating demand in winter could be reduced by $23 \mathrm{MWh}$, when mixing air from an unheated rooftop greenhouse, without a large roof window. The potential saved would increase to 
$28 \mathrm{MWh}$ if the greenhouse has a large rooftop window, and up to $40 \mathrm{MWh}$ if the air in the greenhouse was also benefiting from air mixing from the Corridor (Zone 1), without a roof window. Furthermore, the mass of crops grown in the greenhouse with each of these scenarios must be considered: without a roof window, $11 \mathrm{~kg}$ of crop dry matter was grown, increasing to $13 \mathrm{~kg}$ when the air from the corridor air was mixed into the greenhouse, and $23 \mathrm{~kg}$ when the greenhouse has a large rooftop window. On the other hand, energy use for cooling the Classroom was larger in summer by $18 \mathrm{MWh}$ when the greenhouse zone had a large roof window, due to the varying effects on plant temperatures, transpiration and solar radiation in the greenhouse. The model results suggest that ventilating the classroom air from the greenhouse zone, when it is warm and low $\mathrm{CO}_{2}$, could reduce the energy demand for heating and cooling the classroom by 33 to $57 \%$ a year, depending on how much the greenhouse was heated itself, while at the same time producing crops. The co-simulation tool could thus be used to determine the optimal air mixing configuration.

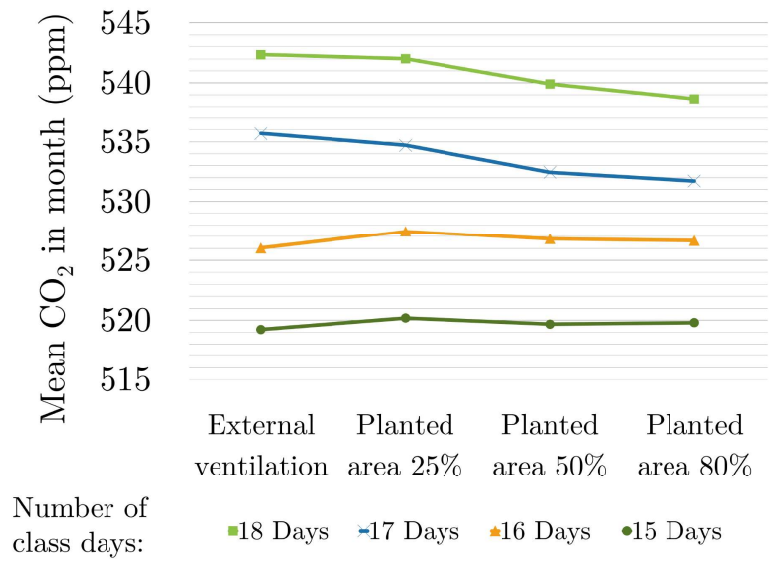

Figure 9: $\mathrm{CO}_{2}$ levels in the classroom with external ventilation, and air mixing from the greenhouse with different planted areas.

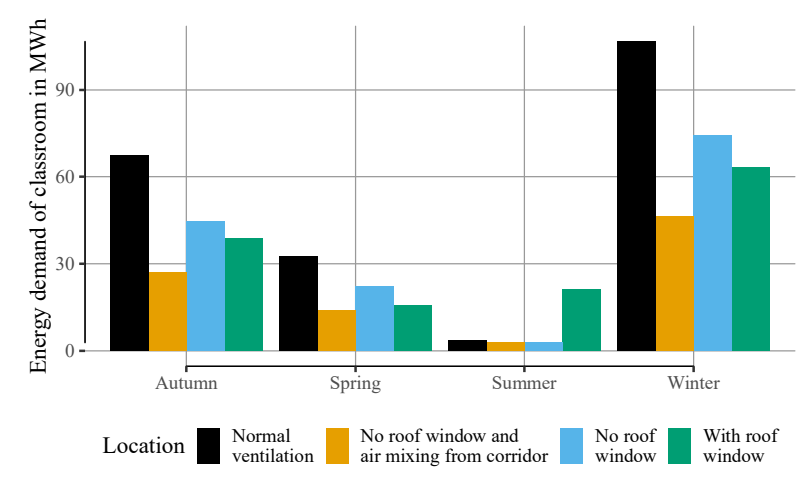

Figure 10: Energy demand for heating and cooling the classroom zone (zone 3), when ventilating the classroom with external air (black) and different configurations of the greenhouse zone.

\section{Conclusions}

An archetype school building with a greenhouse zone is co-simulated with a plant simulation model. The co-simulation enables examination of the influence of a rooftop greenhouse in a school environment. This approach can be used to fine-tune the integration of a greenhouse to yield maximum benefits: (a) to reuse waste streams such as high $\mathrm{CO}_{2}$ levels and temperatures in the building as inputs into the greenhouse to create an optimal environment for crop growth, and (b) to beneficially use the lower temperatures and $\mathrm{CO}_{2}$ levels in the greenhouse zone to reduce heating and cooling loads elsewhere in the building. Preliminary results suggest that if a sufficient density of planting is incorporated into a fully coupled system, $\mathrm{CO}_{2}$ levels and air temperatures can be reduced with a corresponding impact on the energy demand requirements for ventilation. Furthermore, the warmer input air from the corridor, enriched $\mathrm{CO}_{2}$ enhances crop growth within the greenhouse.

In the past, lack of data, and the operation of greenhouse engineers and building engineers in silos has led to the separation of these two modelling fields. The novelty of the study presented here is the implementation of dynamic thermodynamic effects of plant growth on the building environment in terms of temperature, humidity, and $\mathrm{CO}_{2}$ levels. The model can be used to quantify the environmental co-benefits of integrating controlled vegetated areas with human occupied buildings.

\section{Acknowledgement}

We would like to thank Willy Bernal for his assistance in using the MLE+ tool. This project was funded by the EPSRC.

\section{References}

Benis, K., C. Reinhart, and P. Ferrao (2017). Development of a simulation-based decision support workflow for the implementation of BuildingIntegrated Agriculture (BIA) in urban contexts. Journal of Cleaner Production 147, 589-602.

Benis, K., I. Turan, C. F. Reinhart, and P. Ferrão (2018). Putting rooftops to use - A Cost-Benefit Analysis of food production vs. energy generation under Mediterranean climates. Cities 78, 166-179.

Bernal, W., M. Behl, T. Nghiem, and R. Mangharam (2014). Campus-wide integrated building energy simulation. 2014 ASHRAE/IBPSA-USA Building Simulation Conference (December), 227-234.

(2016). National Calculation Methodology (NCM) modelling guide (for buildings other than dwellings in England).

Sustain (2016). Reaping Rewards II - Measuring and valuing urban food growing. 
DCLG (2017). Energy Performance of Buildings Data: England and Wales. Department for Communities and Local Government.

Despommier, D. (2011). The vertical farm: Controlled environment agriculture carried out in tall buildings would create greater food safety and security for large urban populations. Journal fur Verbraucherschutz und Lebensmittelsicherheit 6(2), 233-236.

Department for Education (2003). Building Bulletin 87 - Guidelines for environmental design in schools.

Department for Education (2014). Building Bulletin 103 - Area guideines for mainstream schools.

Department for Education (2018). Schools, Pupils, and Their Characteristics.

Goldstein, B., M. Hauschild, J. Fernández, and M. Birkved (2016, 11). Testing the environmental performance of urban agriculture as a food supply in northern climates. Journal of Cleaner Production 135, 984-994.

Jans-Singh, M., H. Gillard, R. Ward, and R. Choudhary (2018). Integrating Hydroponics into Office Buildings. In Proceedings from PLEA2018: Passive and Low Energy Architecture Conference.

Kozai, T. (2016). Plant Factory - An Indoor Vertical Farming System for Efficient Quality Food Production. Oxford, UK: Elsevier Inc.

Kulak, M., A. Graves, and J. Chatterton (2013). Reducing greenhouse gas emissions with urban agriculture: A Life Cycle Assessment perspective. Landscape and Urban Planning 111, 68-78.

Léveillé-Guillemette, F. and D. Monfet (2016). Comparison of different mechanical systems models for a passive solar greenhouse with two thermal zones. Proceedings froms BSO16: USA.

Martellozzo, F., J. S. Landry, D. Plouffe, V. Seufert, P. Rowhani, and N. Ramankutty $(2014,5)$. Urban agriculture: A global analysis of the space constraint to meet urban vegetable demand. Environmental Research Letters 9(6), 064025.

Nadal, A., P. Llorach-Massana, E. Cuerva, E. LópezCapel, J. I. Montero, A. Josa, J. Rieradevall, and M. Royapoor (2017). Building-integrated rooftop greenhouses: An energy and environmental assessment in the mediterranean context. Applied Energy 187, 338-351.

Nadal, A., O. Pons, E. Cuerva, J. Rieradevall, and A. Josa $(2018,6)$. Rooftop greenhouses in educational centers: A sustainability assessment of urban agriculture in compact cities. Science of The Total Environment 626, 1319-1331.
New York Sun Works (2018). Impact New York Sun Works.

Orsini, F., R. Kahane, R. Nono-Womdim, and G. Gianquinto $(2013,10)$. Urban agriculture in the developing world: A review. Agronomy for Sustainable Development 33(4), 695-720.

Sanyé-Mengual, E., J. Oliver-Solà, J. I. Montero, and J. Rieradevall (2015). An environmental and economic life cycle assessment of rooftop greenhouse (RTG) implementation in Barcelona, Spain. Assessing new forms of urban agriculture from the greenhouse structure to the final product level. International Journal of Life Cycle Assessment 20(3), 350-366.

Specht, K., R. Siebert, I. Hartmann, U. B. Freisinger, M. Sawicka, A. Werner, S. Thomaier, D. Henckel, H. Walk, and A. Dierich (2013). Urban agriculture of the future: an overview of sustainability aspects of food production in and on buildings. Agriculture and Human Values, 1-19.

Verisk Analytics (2017). UKMap User Guide.

Thomaier, S., K. Specht, D. Henckel, A. Dierich, R. Siebert, U. B. Freisinger, and M. Sawicka (2015, 2). Farming in and on urban buildings: Present practice and specific novelties of ZeroAcreage Farming (ZFarming). Renewable Agriculture and Food Systems 30(01), 43-54.

Tian, W. and R. Choudhary $(2012,11)$. A probabilistic energy model for non-domestic building sectors applied to analysis of school buildings in greater London. Energy and Buildings 54, 1-11.

Vanthoor, B. H. E. (2011). A model-based greenhouse design method. Ph. D. thesis, Wageningen University.

Ward, R., R. Choudhary, C. Cundy, G. Johnson, and A. McRobie (2015). Simulation of plants in buildings; incorporating plant-air interactions in building energy simulation. In 14 th International Conference of IBPSA - Building Simulation 2015, BS 2015, Conference Proceedings.

Ward, R., M. Jans-Singh, and R. Choudhary (2018). Quantifying the Environmental and Energy Benefits of Food Growth in the Urban Environment. In T. Kozai (Ed), Smart Plant Factory - The Next Generation Indoor Vertical Farms, Chapter 17. Chiba, Japan: Springer. 